\title{
Quantitative Phytochemical Profile, Antioxidant and Lipase Inhibitory Potential of Leaves of Momordica charantia L. and Psoralea corylifolia L
}

\author{
PUSHPA KARALE, S. C. DHAWALE* AND M. A. KARALE1
}

Department of Pharmacology, School of Pharmacy, Swami Ramanand Teerth Marathwada University, Nanded, Maharashtra 431606, ${ }^{1}$ Department of Microbiology, Dayanand Science College, Latur, Maharashtra 413523, India

Karale et al.: Antioxidant and Lipase Inhibitory Potential of Indian Medicinal Plants

\begin{abstract}
Medicinal plants have recently gained popularity and are now commonly used to treat a variety of diseases. The aim of this research was to evaluate antioxidant and anti-lipase activities of two commonly used medicinal plants in vitro. The solvents like chloroform, acetone and $70 \%$ ethanol were used to extract the dried leaves of Momordica charantia and Psoralea corylifolia. Folin-Ciocateu's reagent and the aluminum chloride colorimetry process were used to determine the total phenolic and flavonoid contents, respectively. Further the extracts were screened for in vitro antioxidant activity, analyzed by 2,2-diphenyl1-picrylhydrazyl radical scavenging activity and ferric reducing antioxidant power assay. Using pancreatic lipase enzyme inhibition, the anti-lipase potential of extracts was studied and compared to that of the reference drug orlistat. The phytochemical analysis revealed that the ethanol extract of Momordica charantia had the highest total phenolic and total flavonoid content $(89.96 \pm 0.29 \mathrm{mg}$ gallic acid equivalents/g of dry extract; $82.55 \pm 0.03 \mathrm{mg}$ quercetin equivalents/g of dry extract, respectively) of all the plant extracts examined. The ethanol extract of Momordica charantia exhibited substantial radical scavenging and ferric reducing potential, with $\mathrm{IC}_{50}$ values of $96.85 \pm 0.04 \mu \mathrm{g} / \mathrm{ml}$ and $99.43 \pm 0.06 \mu \mathrm{g} / \mathrm{ml}$, respectively. Anti-lipase activity was found in all of the extracts. The ethanol extract of Momordica charantia, on the other hand, demonstrated strong anti-lipase activity, with an $\mathrm{IC}_{50}$ value of $27.70 \pm 0.15 \mu \mathrm{g} / \mathrm{ml}(\mathrm{p}<0.01)$. The standard drug orlistat $(18.15 \pm 0.34 \mu \mathrm{g} / \mathrm{ml})$ showed the greatest anti-lipase activity. Overall, Momordica charantia leaf extracts exhibited greater antioxidant and anti-lipase activity than Psoralea corylifolia. Momordica charantia and Psoralea corylifolia were found to be powerful antioxidants and pancreatic lipase inhibitors. A daily supplement of these plants, according to our findings, can aid in the reduction of obesity.
\end{abstract}

Key words: Momordica charantia, Psoralea corylifolia, pancreatic lipase, radical scavenging activity, ferric reducing antioxidant power assay

Oxidative stress is an important risk factor in the pathogenesis of numerous chronic diseases such as asthma, inflammatory arthropathy, diabetes, cardiovascular diseases, neurodegenerative diseases, cancer, aging as well as atherosclerosis ${ }^{[1]}$. Any material that prevents or slows oxidative damage to a target molecule is considered an antioxidant ${ }^{[2]}$. The ability of an antioxidant to trap free radicals is its most essential characteristic. Since ancient times, medicinal plants have been thought to be safe and effective antioxidants. Antioxidant compounds found in nature, such as phenolics, flavonoids and polyphenols, may be able to scavenge free radicals and thus inhibit the oxidative mechanism $^{[3]}$.

*Address for correspondence

E-mail: shashiprathmesh@gmail.com

January-February 2022
Obesity is characterized by Body Mass Index (BMI), which is measured as body weight divided by square of height ${ }^{[4]}$. A BMI of $25.0-29.9 \mathrm{~kg} / \mathrm{m}^{2}$ is defined as overweight, while a BMI exceeding $30 \mathrm{~kg} / \mathrm{m}^{2}$ is considered as obese. An extreme obesity is defined as a BMI of greater than $40 \mathrm{~kg} / \mathrm{m}^{2}$. Obesity may be caused by a variety of factors, including diet, genetic abnormalities, sedentary lifestyle and psychological factors $^{[5]}$. Obesity has been linked to an increase in

This is an open access article distributed under the terms of the Creative Commons Attribution-NonCommercial-ShareAlike 3.0 License, which allows others to remix, tweak, and build upon the work non-commercially, as long as the author is credited and the new creations are licensed under the identical terms

Accepted 15 February 2022

Revised 15 December 2021

Received 07 July 2021

Indian J Pharm Sci 2022;84(1):189-196 
the prevalence of metabolic disorders such as type 2 diabetes, liver disease, kidney disease, high blood pressure, cardiac disease, gallbladder disease and some types of cancer ${ }^{[6]}$. The function of lipolytic enzymes involved in fatty acid metabolism in adipose tissue determines the regulation and availability of fatty acids and triglycerides in biological responses ${ }^{[7]}$. The characterization and discovery of many genes involved in lipid metabolism has resulted in a large pool of potential targets for treating obesity and other metabolic syndromes ${ }^{[8]}$.

Pancreatic lipase is the most effective lipid digesting enzyme, generating the lipolytic product beta ( $\beta$ )-monoglyceride and long chain saturated and polyunsaturated fatty acids from dietary triglycerides. Pancreatic lipase inhibition is a promising targeted method for the discovery of potent anti-obesity agents ${ }^{[9]}$. Orlistat is a long-term pancreatic lipase inhibitor discovered and modified from Streptomyces toxytricini that is currently used to treat obesity. However, this medication causes a range of side effects such as fatty diarrhea, stool urgency, fecal incontinence, allergies and liver function impairment ${ }^{[10,11]}$. In several countries, traditional medicinal plants have been used to treat obesity and body weight management. Natural bioactive compounds including flavonoids and polyphenols have recently been shown to be involved in the treatment of obesity ${ }^{[12]}$. As a result, natural compounds have received significant attention in recent years in order to develop safer and more powerful pancreatic lipase inhibitors. Natural compound intake, combined with sufficient dietary changes and exercise, is gradually becoming one of the most prominent complementary and alternative medicine strategies for obesity management ${ }^{[13]}$.

Momordica charantia (M. charantia) is a climber in the Cucurbitaceae family that has been used in Chinese and Ayurvedic herbal medicine to treat hypoglycemia and diabetes ${ }^{[14]}$. In India, China, Japan and other Asian countries, $M$. charantia, grown as a valuable vegetable crop. Previous research has shown that the plant has antibacterial, antiviral, antidiabetic, antifertility, abortifacient, anti-ulcer and antimalarial properties, as well as immunomodulatory properties ${ }^{[15]}$. Psoralea corylifolia (P. corylifolia) (Leguminosae) is a popular herb used in traditional Indian and Chinese herbal medicine to treat skin diseases. Plant extracts have been reported to have antibacterial, anti-tumor, antioxidant, anti-inflammatory, immunomodulatory and antifungal effects $^{[16]}$. At the moment, the potential of natural products for the treatment of obesity is relatively unexplored, but they may be an excellent alternative for the effective and safe development of antiobesity drugs. To the best of the author's knowledge, there have been no previous studies on the effects of $M$. charantia and P. corylifolia leaf extracts on the lipase enzyme inhibition and our research is the first on these plants sections, as numerous studies were carried out on fruits and seeds of these plants respectively. This study investigated crude extracts from natural sources as potential antioxidant and anti-obesity agents by evaluating their radical scavenging and anti-lipase activity.

\section{MATERIALS AND METHODS}

\section{Chemicals and drugs:}

Petroleum ether, acetone, ethanol were purchased from S. D. Fine, Mumbai, India. Folin-Ciocateu's reagent, ascorbic acid, Dimethyl Sulfoxide (DMSO), para-Nitrophenyl Butyrate (p-NPB), Porcine Pancreatic Lipase ((PPL); Type II: From porcine pancreas), 2,2-Diphenyl-1-Picryhydrazyl (DPPH), orlistat were purchased from Sigma (United States of America (USA)). All other chemicals were of analytical grade.

\section{Collection and extraction of plant materials:}

Two Indian medicinal plants $M$. charantia and $P$. corylifolia were selected based on traditional medicinal uses. Plant leaves were collected from various locations from local areas. The taxonomic identification and authentication was conducted by Dr. Priyanka Ingle, Scientist, Botanical Survey of India, Western Regional Centre, Pune (Voucher no: BSI/WRC/100-1/ TECH./2019/76; BSI/WRC/100-1/Tech./2020/113).

The plant leaves were washed under running water and dried in the shade. To make a coarse powder, dried plant samples were ground in a blender. With petroleum ether, $500 \mathrm{~g}$ of field plant materials were defatted. The plant materials were then extracted successively using chloroform, acetone and $70 \%$ ethanol by maceration method of extraction. The extracts were then filtered through Whatman No. 1 filter paper and the solvent was removed by vacuum evaporation at $40^{\circ}-45^{\circ}$. The dried extracts were stored at $4^{\circ}-8^{\circ}$ prior to the analysis, two or three batches of the extracts were obtained depending on the plant sample.

\section{Phytochemical analysis:}

The key secondary metabolites of various extracts of $M$. charantia and $P$. corylifolia were screened using qualitative and quantitative phytochemical tests. 
Based on previously mentioned standard protocols, several qualitative phytochemical tests were performed to determine the existence of alkaloids, phenolics, saponins, tannins, flavonoids, carbohydrates, amino acids, terpenoids, steroids and glycosides in the plant extract $^{[17]}$.

The Total Phenolic Content (TPC) of the extracts were calculated using a previous method ${ }^{[18]}$. TPC of various extracts of $M$. charantia and $P$. corylifolia were calculated from a calibration curve using gallic acid $(25-400 \mu \mathrm{g} / \mathrm{ml})$ as a standard. The results were expressed as milligram Gallic Acid Equivalent/gram Dry Weight of Extract (mg GAE/g of DE). The Total Flavonoid Content (TFC) of extracts were determined using the aluminum chloride-based colorimetric technique ${ }^{[19]}$. TFC of extracts were calculated from a calibration curve using quercetin $(25-400 \mu \mathrm{g} / \mathrm{ml})$ as a standard. The TFC was expressed as milligram Quercetin Equivalent/gram Dry Weight of Extract (mg QE/g of DE).

\section{Antioxidant activity:}

The antioxidant activity of the crude extracts were screened by using DPPH free radical scavenging assay as described previously ${ }^{[20,21]}$. The dried crude chloroform, acetone and hydroalcoholic extracts were each dissolved to five different concentrations $(25,50,100,150,200$ and $250 \mu \mathrm{g} / \mathrm{ml})$ in ethanol. The reaction mixture, containing $50 \mu$ of the desired extracts concentration in ethanol and $5 \mathrm{ml}$ of $0.004 \%(\mathrm{w} / \mathrm{v})$ of DPPH solution were added and incubated at $37^{\circ}$ for $30 \mathrm{~min}$ in a relatively dark place. After incubation, the absorbance was measured at $517 \mathrm{~nm}$ using spectrophotometer (Shimadzu, Japan). Ascorbic acid was used as standard drug for comparison. The DPPH radical scavenging activity was then calculated from equation

DPPH scavenging effect $(\%)=\left(\mathrm{A}_{0}-\mathrm{A} / \mathrm{A}_{0}\right) \times 100$

Where, $\mathrm{A}_{0}$ is the absorbance of negative control (0.004\% DPPH solution) and A is the absorbance in presence of extracts. The results were reported as halfmaximal inhibitory concentration $\left(\mathrm{IC}_{50}\right.$ ) values.

The Ferric Reducing Antioxidant Power (FRAP) ability of extracts were investigated by using the potassium ferricyanide-ferric chloride method. Briefly, $0.2 \mathrm{ml}$ of each of the extracts at different concentrations or ascorbic acid, $2.5 \mathrm{ml}$ of phosphate buffer (pH 6.6, 0.2 M) and $2.5 \mathrm{ml}$ of potassium ferricyanide $(1 \%)$ were mixed and incubated for $20 \mathrm{~min}$ at $50^{\circ}$, to reduce ferricyanide into ferrocyanide. $2.5 \mathrm{ml}$ of $10 \%$ trichloroacetic acid $(\mathrm{w} / \mathrm{v})$ were added to stop the reaction and centrifuged at $1000 \mathrm{rpm}$ for $10 \mathrm{~min}$. Finally, $2.5 \mathrm{ml}$ of the upper layer was mixed with $2.5 \mathrm{ml}$ of distilled water and $0.5 \mathrm{ml}$ of $0.1 \%$ of $\mathrm{FeCl}_{3}$ and the absorbance was measured at $700 \mathrm{~nm}^{[22]}$. Ascorbic acid was used as a reference compound.

\section{Pancreatic lipase inhibition:}

Pancreatic lipase activity was measured using $\mathrm{p}-\mathrm{NPB}$ as a substrate. The previously described spectrophotometric method was used for measuring the pancreatic lipase inhibitory activity with slight modification ${ }^{[23,24]}$. A stock solution of p-NPB was prepared by dissolving $20.9 \mathrm{mg}$ of $\mathrm{p}-\mathrm{NPB}$ in $2 \mathrm{ml}$ of acetonitrile. The final concentrations of plant extracts $(50,100,200,300$ and $400 \mu \mathrm{g} / \mathrm{ml})$ were prepared in $10 \%$ DMSO. The stock solution of pancreatic lipase enzyme $(1 \mathrm{mg} / \mathrm{ml})$ was prepared in $0.1 \mathrm{mM}$ potassium phosphate buffer $(\mathrm{pH}$ 6.0) immediately before being used. $0.2 \mathrm{ml}$ of the various concentrations $(50,100,200,300,400 \mu \mathrm{g} / \mathrm{ml})$ of plant extract were added to test tubes containing $0.1 \mathrm{ml}$ of PPL.

Then the resulting mixtures were made up to $1 \mathrm{ml}$ by adding Tris (Hydroxymethyl) Aminomethanehydrochloride (Tris-HCl) buffer (Dissolve $12.1 \mathrm{~g}$ of Tris base in $80 \mathrm{ml}$ of water, adjust $\mathrm{pH}$ by slowly adding concentrated $\mathrm{HCl}$ ) of $\mathrm{pH} 7.4$ and incubated at $25^{\circ}$ for $15 \mathrm{~min}$. After the incubation period, the p-NPB $(0.1 \mathrm{ml})$ solution was added to each test tube and the mixture was again incubated for $30 \mathrm{~min}$ at $37^{\circ}$. After incubation, the amount of p-nitrophenol released in the reaction was measured at $405 \mathrm{~nm}$ using Ultraviolet (UV)-visible spectrophotometer (Shimadzu, Japan). The same procedure was repeated for the all extracts and for orlistat as a positive control using the same concentrations as mentioned above. All the established tests were performed in triplicate and the Inhibitory activity (I \%) was calculated by using the formula:

$\mathrm{I} \%=\left(\mathrm{Abs}_{(\mathrm{Control})}-\mathrm{Abs}_{(\text {Sample) }} / \mathrm{Abs}_{(\text {Control) }}\right) \times 100$

Where $\mathrm{Abs}_{(\mathrm{Control})}$ was the absorbance without sample, $\mathrm{Abs}_{\text {(Sample) }}$ was the absorbance of sample extract.

\section{Data analysis:}

All the assays were carried out in triplicate $(n=3)$. The results were expressed as mean \pm Standard Deviation (SD) and the statistical difference for more than two samples was determined by using one-way Analysis of Variance (ANOVA) and the Dunnett's comparison test (GraphPad InStat software) was performed where, 
all the tested extracts compare with the control group (ascorbic acid, orlistat). A $p$ value of $<0.05$ was considered to be significant.

\section{RESULTS AND DISCUSSION}

The preliminary qualitative phytochemical analysis as depicted in Table 1, revealed the presence of alkaloids, glycosides, triterpenoids, carbohydrates, steroids, saponins, flavonoids and phenols in both the plant extracts abundantly. However, the tannins and amino acids were not detected. The results of quantitative analysis showed that the chloroform, acetone and ethanol extracts of $M$. charantia and $P$. corylifolia were characterized by the presence of considerable amount of TPC and TFC (fig. 1). The highest amount of TPC and TFC was found in Ethanol extract of M. charantia (EMC) as $89.96 \pm 0.29 \mathrm{mg} \mathrm{GAE} / \mathrm{g}$ of DE and $82.55 \pm 0.03 \mathrm{mg} \mathrm{QE} / \mathrm{g}$ of DE respectively, followed by Ethanol extract of $P$. corylifolia (EPC) (87.31 $\pm 0.36 \mathrm{mg} \mathrm{GAE} / \mathrm{g}$ of DE; $79.07 \pm 0.09 \mathrm{mg} \mathrm{QE} / \mathrm{g}$ of DE).
Antioxidant activity is a complex procedure and is influenced by several factors and happening through several mechanisms, which cannot be fully explored with single method. Therefore, it is essential to perform more than one type of methods to measure antioxidant activity to understand different mechanisms. In this study two alternative assays were performed to assess the antioxidant activity of $M$. charantia and $P$. corylifolia. All extracts of $M$. charantia and P. corylifolia were able to reduce the stable DPPH into yellow coloured DPPH-H. As summarized in Table 2, the ethanol extracts obtained from $M$. charantia and $P$. corylifolia had the strongest Radical Scavenging Activity (RSA) with $\mathrm{IC}_{50}$ values of $96.85 \pm 0.04 \mu \mathrm{g} / \mathrm{ml}$ and $115.82 \pm 0.06$ respectively. However, the lowest RSA was observed in the Acetone extract of M. charantia (ACMC) and Acetone extract of P. corylifolia (ACPC) (163.26 $\pm 0.05 \mu \mathrm{g} / \mathrm{ml}$ and $172.27 \pm 0.04 \mu \mathrm{g} / \mathrm{ml})$. All the extracts were less effective than the standard antioxidant ascorbic acid with $\mathrm{IC}_{50}$ value of $47.47 \pm 0.04 \mu \mathrm{g} / \mathrm{ml}$ (fig. 2).

TABLE 1: QUALITATIVE PHYTOCHEMICAL ANALYSIS OF $M$. charantia AND P. corylifolia LEAF EXTRACTS

\begin{tabular}{|c|c|c|c|c|c|c|c|}
\hline \multirow{2}{*}{ Constituents } & \multirow{2}{*}{ Tests performed } & \multicolumn{3}{|c|}{ M. charantia } & \multicolumn{3}{|c|}{ P. corylifolia } \\
\hline & & CHMC & ACMC & EMC & CHPC & ACPC & EPC \\
\hline Glycosides & Keller-Killani test & + ve & + ve & $+v e$ & + ve & + ve & + ve \\
\hline Alkaloids & Wagner's test & + ve & + ve & + ve & + ve & + ve & + ve \\
\hline Flavonoids & Ammonia test & + ve & $+v e$ & + ve & + ve & + ve & + ve \\
\hline Phenolics & Ferric chloride & + ve & + ve & + ve & + ve & + ve & + ve \\
\hline Carbohydrates & Fehling test & + ve & + ve & + ve & + ve & + ve & + ve \\
\hline Saponins & Foam test & + ve & + ve & + ve & + ve & + ve & + ve \\
\hline Steroids & Liebermann test & +ve & + ve & + ve & + ve & $+v e$ & + ve \\
\hline Tannins & Ferric chloride & -ve & -ve & -ve & -ve & -ve & -ve \\
\hline Amino acids & Ninhydrin test & -ve & -ve & -ve & -ve & -ve & -ve \\
\hline
\end{tabular}

Note: +ve: Positive; -ve: Negative. CHMC: Chloroform extract of $M$. charantia; ACMC: Acetone extract of M. charantia; EMC: Ethanol extract of $M$. charantia; CHPC: Chloroform extract of P. corylifolia; ACPC: Acetone extract of P. corylifolia; EPC: Ethanol extract of $P$. corylifolia
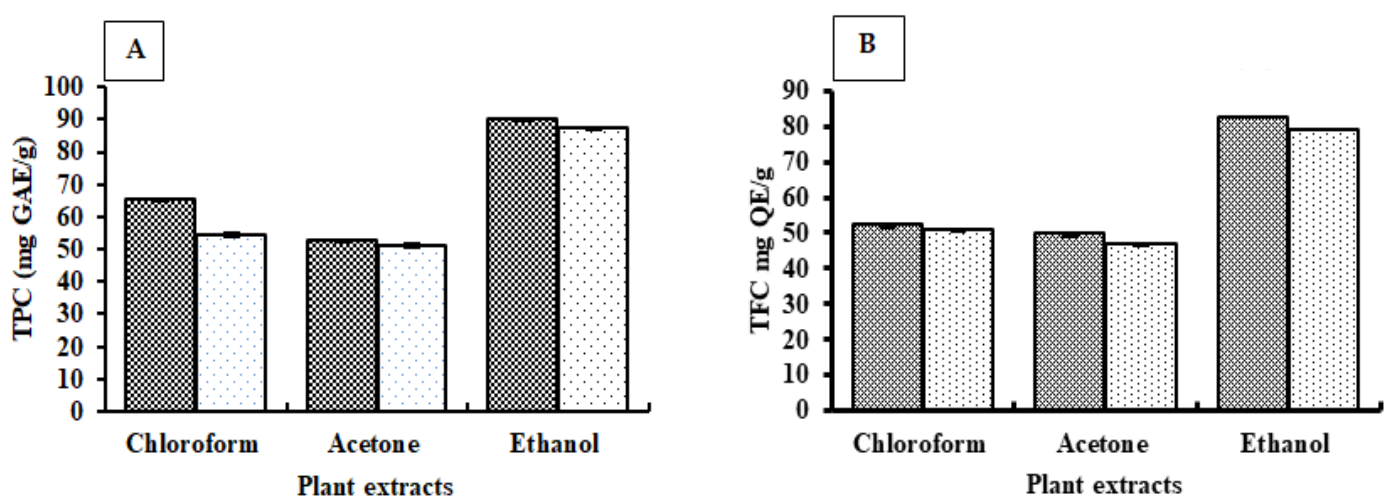

Fig. 1: (A) TPC of different extracts of $M$. charantia and $P$. corylifolia. TPC expressed as mg GAE/g of DE. The data were presented as mean $\pm \mathrm{SD}(\mathrm{n}=3)$; (B) TFC of different extracts of $M$. charantia and $P$. corylifolia. TFC expressed as $\mathrm{mg} \mathrm{QE} / \mathrm{g}$ of DE. The data were expressed as mean $\pm \mathrm{SD}(\mathrm{n}=3),\left(\mathbb{Q}_{1}\right)$ M. charantia $;(\square)$ P. corylifolia 
Antioxidant potential for FRAP of extracts of $M$. charantia and $P$. corylifolia were presented in fig. 3. The strongest activity of reducing ion Ferric ion $\left(\mathrm{Fe}^{3+}\right)$ to Ferrous ion $\left(\mathrm{Fe}^{2+}\right)$ was noted for EMC $\left(\mathrm{IC}_{50}=99.43 \pm 0.06 \mu \mathrm{g} / \mathrm{ml}\right)$. A slightly lower activity was observed for EPC with $\mathrm{IC}_{50}$ value of $102.81 \pm 0.05 \mu \mathrm{g} /$ $\mathrm{ml}$. At concentrations of $25-250 \mu \mathrm{g} / \mathrm{ml}$, all extracts from leaves of $M$. charantia and P. corylifolia displayed an antioxidant effect by reducing ferric ion and the antioxidant effect of all samples was in the order of ascorbic acid $>$ EMC $>$ EPC $>$ Chloroform extract of $P$. corylifolia (CHPC) $>$ Chloroform extract of M. charantia $(\mathrm{CHMC})>\mathrm{ACMC}>\mathrm{ACPC}$. All the extracts were less effective than the standard antioxidant ascorbic acid $\left(\mathrm{IC}_{50}=53.90 \pm 0.06 \mu \mathrm{g} / \mathrm{ml}\right)$.

The chloroform, acetone and ethanol extracts of $M$. charantia and P. corylifolia were investigated for

\begin{tabular}{|c|c|}
\hline Extracts and ascorbic acid & $\mathrm{IC}_{50} \pm \mathrm{SD}$ (DPPH) \\
\hline $\mathrm{CHMC}$ & $143.36 \pm 0.14^{* *}$ \\
\hline ACMC & $163.26 \pm 0.05^{* *}$ \\
\hline EMC & $96.85 \pm 0.04^{* *}$ \\
\hline CHPC & $159.83 \pm 0.06^{* *}$ \\
\hline ACPC & $172.27 \pm 0.04^{* *}$ \\
\hline EPC & $115.82 \pm 0.06^{* *}$ \\
\hline Ascorbic acid & $47.47 \pm 0.04$ \\
\hline
\end{tabular}

Note: Values were expressed as mean $\pm S D,{ }^{* *} p<0.01$ was considered significant as compared with that of standard ascorbic acid anti-lipase activity at a concentration of $50-400 \mu \mathrm{g} / \mathrm{ml}$. The pancreatic lipase inhibitory activities of extracts and orlistat were reported in Table 3. The inhibitory effects $\left(\mathrm{IC}_{50}\right)$ of plant extracts and the standard drug (orlistat) shown to be dose dependent. The lipase enzyme activity decreased as concentration of plant extracts and orlistat increased. Fig. 4A and fig. 4B depicted the degree of lipase inhibition for plant extracts of M. charantia and P. corylifolia and orlistat. From the fig. 4A and fig. 4B, we can conclude that all the extracts of $M$. charantia and $P$. corylifolia showed significant anti-lipase activity. Overall, the EMC leaves revealed the best anti-lipase potential with significantly lower $\mathrm{IC}_{50}$ values of $27.70 \pm 0.15 \mu \mathrm{g} / \mathrm{ml}$ and the ACPC revealed a very poor lipase inhibition activity $\left(\mathrm{IC}_{50}\right.$ values $\left.=74.82 \pm 0.28 \mu \mathrm{g} / \mathrm{ml}\right)$.

Free radical-induced oxidative stress is responsible for pathogenesis and damage to the body, while antioxidants are essential in protecting the body from oxidative stress-related damage. In the search for new bioactive compounds from natural sources, the antioxidant ability of $M$. charantia and $P$. corylifolia extracts were investigated. Natural antioxidants present in plants, such as phenolic acids and flavonoids, may be capable of providing resistance to free radical oxidative stress $^{[25,26]}$. The reaction mechanisms of the methods used vary. The DPPH assay, for example, is based on electron and $\mathrm{H}$ atom transfer, while the FRAP assay is based on electron transfer reaction ${ }^{[27-29]}$. Because of the hydrogen-donating property of their hydroxyl groups, plant polyphenols and flavonoids serve as reducing agents and antioxidants ${ }^{[30]}$.

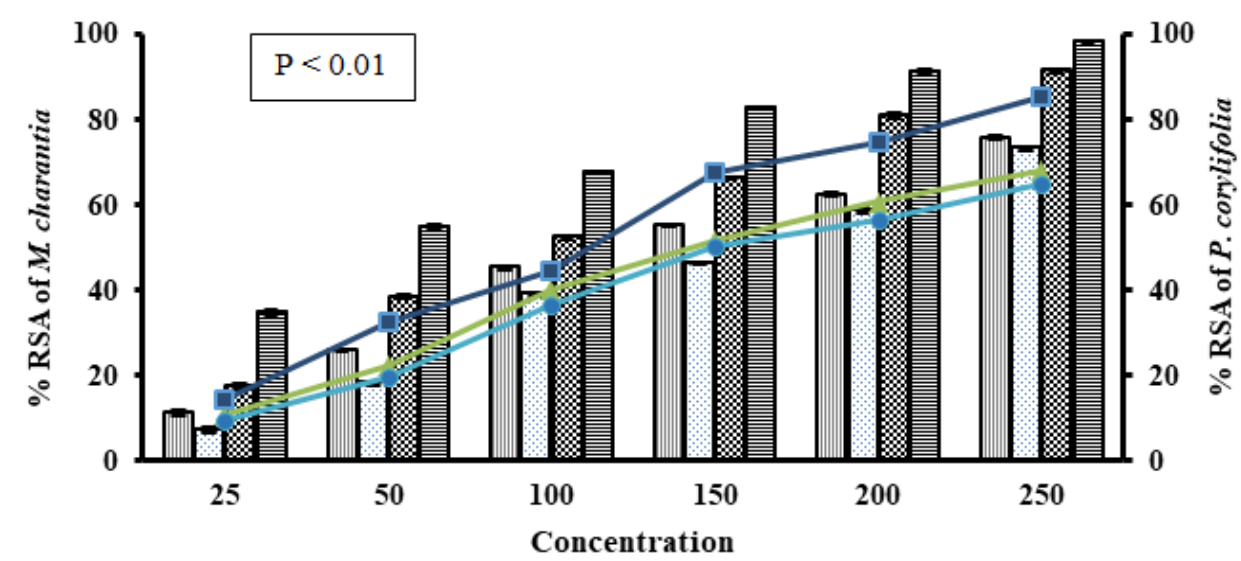

Fig. 2: Percent radical scavenging (DPPH) activity of extracts of $M$. charantia (bars) and $P$. corylifolia (lines). All the extracts were compared with the standard antioxidant ascorbic acid. The data were presented as mean \pm SD (n=3). One way ANOVA were performed and followed by Dunnett's multiple comparisons test where, all the extracts are compared with ascorbic acid. The $p$

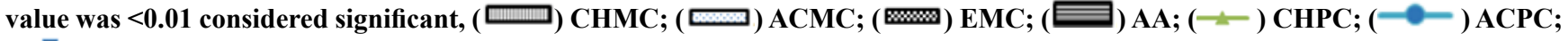
$(-)$ ) EPC 


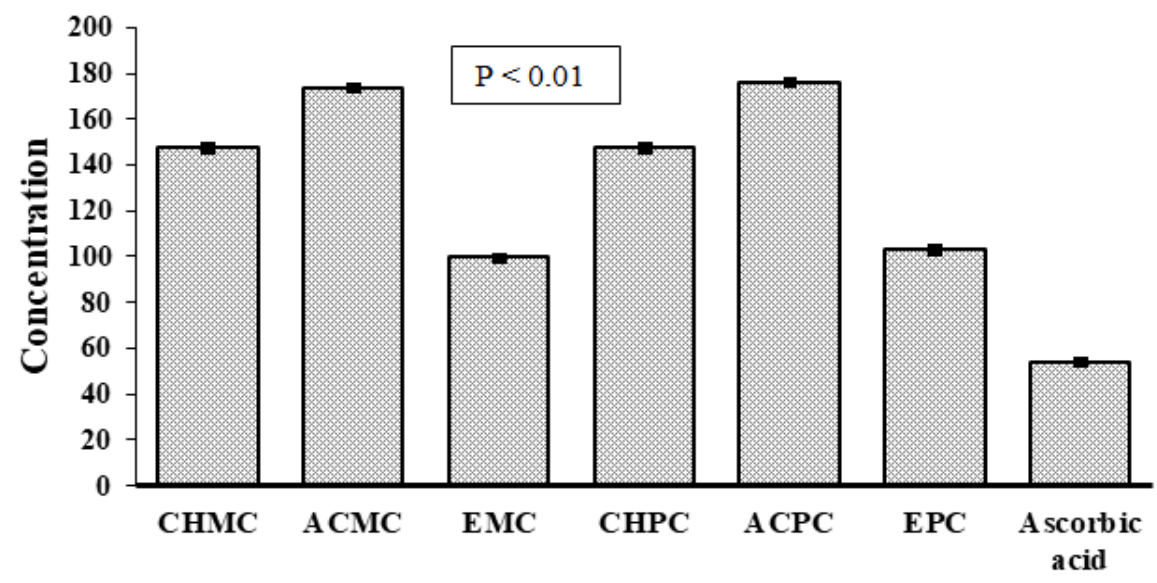

Treatment

Fig. 3: $\mathrm{IC}_{50}$ values of different extracts of selected plant for FRAP antioxidant assay. The data presented as mean $\mathrm{IC}_{50} \pm \mathrm{SD}$. All the experiments were performed in triplicate. The $p$ value was $<0.01$ considered significant following ANOVA and Dunnett's multiple comparisons test

TABLE 3: PANCREATIC LIPASE INHIBITORY POTENTIAL AS IC ${ }_{50}$ VALUES OF DIFFERENT EXTRACTS OF SELECTED PLANTS AND ORLISTAT

\begin{tabular}{|c|c|c|c|c|}
\hline Plant name & Family & Parts used & Extracts and orlistat & $I C_{50} \pm S D(\mu \mathrm{g} / \mathrm{ml})$ \\
\hline \multirow{3}{*}{ M. charantia } & \multirow{3}{*}{ Cucurbitaceae } & \multirow{3}{*}{ Leaves } & Chloroform (CHMC) & $41.37 \pm 0.41^{* *}$ \\
\hline & & & Acetone (ACMC) & $69.34 \pm 0.46^{* *}$ \\
\hline & & & Ethanol (EMC) & $27.70 \pm 0.15^{* *}$ \\
\hline \multirow{3}{*}{ P. corylifolia } & \multirow{3}{*}{ Leguminosae } & \multirow{3}{*}{ Leaves } & Chloroform (CHPC) & $50.99 \pm 0.58^{* *}$ \\
\hline & & & Acetone (ACPC) & $74.82 \pm 0.28^{* *}$ \\
\hline & & & Ethanol (EPC) & $36.88 \pm 0.14^{* *}$ \\
\hline Standard & - & - & Orlistat & $18.15 \pm 0.34$ \\
\hline
\end{tabular}

Note: Values were expressed as mean $\pm S D(n=3),{ }^{* *} p<0.01$ was considered significant as compared with that of standard orlistat

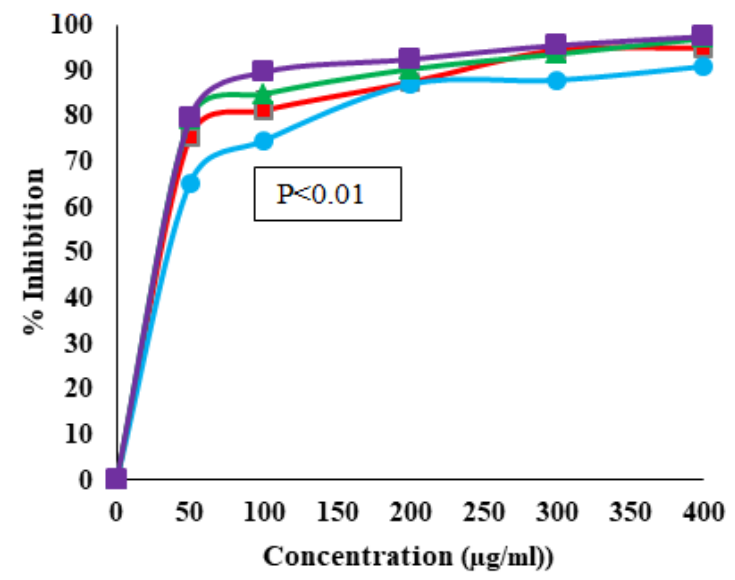

(A)

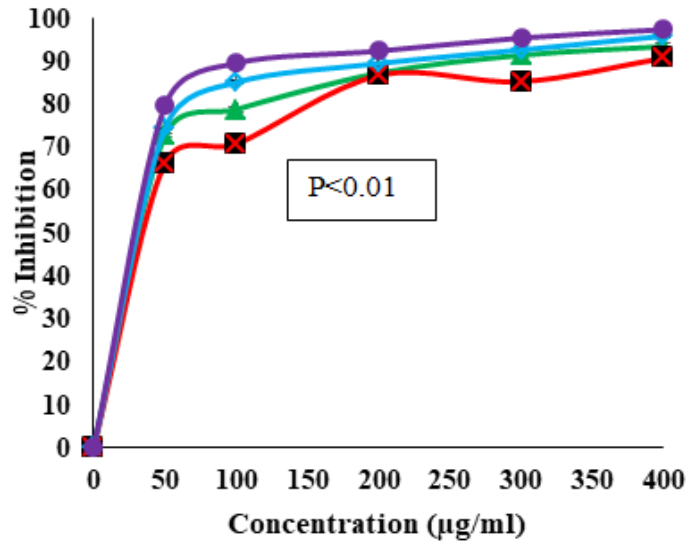

(B)

Fig. 4: (A) The inhibitory effects of different extracts (CHMC, ACMC and EMC) of M. charantia and orlistat on the pancreatic lipase activity. All the data were presented as mean \pm SD $(n=3),(--)$ CHMC; $(-)$ ACMC; $(\rightarrow)$ EMC; ( --$)$ Orlistat; (B) The inhibitory effects of different extracts (CHPC, ACPC and EPC) of $P$. corylifolia and orlistat on the pancreatic lipase activity. All the data were presented as mean \pm SD $(n=3),(-)$ CHPC; $(\rightarrow)$ ACPC

According to the findings, the EMC has the highest antioxidant activity for both the DPPH scavenging assay and the FRAP assay. The TPC and TFC for all the tested extracts were found in the order of EMC $>$ EPC $>$ CHMC $>$ CHPC $>$ ACMC $>$ ACPC. The phenolic acid and flavonoid contents for each sample 
were in accordance with the findings of the DPPH scavenging assay and the FRAP assay. The close relationship between total polyphenolic (phenolic acid and flavonoids) content and antioxidant potential suggests that phenolic compounds play a significant role in medicinal plants antioxidant activities. A strong correlation or direct association between phenolic content and antioxidant potential of the selected plants has been discovered in several studies ${ }^{[31,32]}$.

Because of the significant side effects of current antilipase medications, natural product-based pancreatic lipase inhibitors have emerged as a new player in the fight against obesity. The inhibition of pancreatic lipase activities decreases the digestion of fat-rich foods, resulting in a lower calorie intake ${ }^{[33]}$. One of the most well-studied mechanisms in evaluating the possible effectiveness of natural products as anti-obesity agents is the anti-lipase effect ${ }^{[34]}$. Consumption of edible plants may be a beneficial and healthy treatment option for obesity. They have been designed to promote therapeutic benefits, particularly in the prevention of pathophysiological conditions like obesity, dyslipidaemia, diabetes, hypertension and cancer ${ }^{[35]}$.

Many previous studies, have shown that flavonoids and other phenolic compounds act as PPL enzyme inhibitors by binding to the enzyme-substrate complex, reducing the lipid absorption ${ }^{[36,37]}$. The highest anti-lipase effect was found in the EMC $\left(\mathrm{IC}_{50}=27.70 \pm 0.15 \mu \mathrm{g} / \mathrm{ml}\right)$ and EPC $\left(\mathrm{IC}_{50}=36.88 \pm 0.15 \mu \mathrm{g} / \mathrm{ml}\right)$, which is linked to its high phenolic and flavonoid content.

According to the findings, $M$. charantia and $P$. corylifolia have significant antioxidant and anti-lipase properties. The ethanol leaf extract of $M$. charantia had the highest antioxidant potential of all the extracts, but was less than the standard antioxidant ascorbic acid, according to the DPPH and FRAP assays. Our findings indicated that these edible plants could be used as subsidiary treatment or to replace orlistat in the treatment of obesity. More pharmacological in vivo studies are needed to confirm these findings and to identify the main chemical compounds in these plants responsible for these pharmacological effects using chromatographical isolation of the bioactive compounds.

\section{Funding:}

This study was supported by Chief Minister Special Research Fellowship (CMSRF) 2019 by Chhatrapati Shahu Maharaj Research Training and Human
Development Institute (SARTHI), Pune, Maharashtra, India.

\section{Acknowledgements:}

The authors acknowledge SARTHI, Pune for granting CMSRF fellowship during the research work. The plant authentication provided by the Botanical Survey of India, Western Regional Centre, Pune, Maharashtra, India is duly acknowledged.

\section{Conflict of interests:}

The authors declared no conflict of interest.

\section{REFERENCES}

1. Chiavaroli V, Giannini C, de Marco S, Chiarelli F, Mohn A. Unbalanced oxidant-antioxidant status and its effects in pediatric diseases. Redox Rep 2011;16(3):101-7.

2. Yamagishi SI, Matsui T. Nitric oxide, a janus-faced therapeutic target for diabetic microangiopathy-friend or foe? Pharmacol Res 2011;64(3):187-94.

3. Wu YY, Li W, Xu Y, Jin EH, Tu YY. Evaluation of the antioxidant effects of four main theaflavin derivatives through chemiluminescence and DNA damage analyses. J Zhejiang Univ Sci B 2011;12(9):744-51.

4. Ado MA, Abas F, Mohammed AS, Ghazali HM. Anti-and pro-lipase activity of selected medicinal, herbal and aquatic plants, and structure elucidation of an anti-lipase compound. Molecules 2013;18(12):14651-69.

5. Ojulari OV, Lee SG, Nam JO. Beneficial effects of natural bioactive compounds from Hibiscus sabdariffa L. on obesity. Molecules 2019;24(1):210.

6. Lee SG, Lee YJ, Jang MH, Kwon TR, Nam JO. Panax ginseng leaf extracts exert anti-obesity effects in high-fat diet-induced obese rats. Nutrients 2017;9(9):999.

7. Miyoshi H, Perfield JW, Obin MS, Greenberg AS. Adipose triglyceride lipase regulates basal lipolysis and lipid droplet size in adipocytes. J Cell Biochem 2008;105(6):1430-6.

8. Shi Y, Burn P. Lipid metabolic enzymes: Emerging drug targets for the treatment of obesity. Nat Rev Drug Discov 2004;3(8):695-710.

9. Kim YS, Lee YM, Kim H, Kim J, Jang DS, Kim JH, et al. Anti-obesity effect of Morus bombycis root extract: Antilipase activity and lipolytic effect. $\mathrm{J}$ Ethnopharmacol 2010;130(3):621-4.

10. Baretić M. Targets for medical therapy in obesity. Dig Dis 2012;30(2):168-72.

11. Derosa G, Maffioli P. Anti-obesity drugs: A review about their effects and their safety. Expert Opin Drug Saf 2012;11(3):45971.

12. Abdul Rahman H, Saari N, Abas F, Ismail A, Mumtaz MW, Abdul Hamid A. Anti-obesity and antioxidant activities of selected medicinal plants and phytochemical profiling of bioactive compounds. Int J Food Prop 2017;20(11):2616-29.

13. Marrelli M, Loizzo MR, Nicoletti M, Menichini F, Conforti F. Inhibition of key enzymes linked to obesity by preparations from Mediterranean dietary plants: Effects on $\alpha$-amylase and pancreatic lipase activities. Plant Foods Hum Nutr 2013;68(4):340-6.

14. Wang J, Ryu HK. The effects of Momordica charantia on 
obesity and lipid profiles of mice fed a high-fat diet. Nutr Res Pract 2015;9(5):489-95.

15. Karale P, Dhawale SC, Karale MA. Antiobesity potential and complex phytochemistry of Momordica charantia Linn. with promising molecular targets. Indian J Pharm Sci 2020;82(4):548-61.

16. Li CC, Wang TL, Zhang ZQ, Yang WQ, Wang YF, Chai X, et al. Phytochemical and pharmacological studies on the genus Psoralea: A mini review. Evid Based Complement Alternat Med 2016;2016.

17. Hazarika AN, Saha DI. Preliminary phytochemical screening and evaluation of anti-diarrhoeal activity of ethanolic extract of leaves of Clerodendrum infortunatum. Int J Curr Pharm Res 2017;9(4):143.

18. Toma A, Makonnen E, Mekonnen Y, Debella A, Addisakwattana S. Intestinal $\alpha$-glucosidase and some pancreatic enzymes inhibitory effect of hydroalcholic extract of Moringa stenopetala leaves. BMC Complement Med Ther 2014;14(1):1-5.

19. Adisakwattana S, Chanathong B. Alpha-glucosidase inhibitory activity and lipid-lowering mechanisms of Moringa oleifera leaf extract. Eur Rev Med Pharmacol Sci 2011;15(7):803-8.

20. Nithianantham K, Shyamala M, Chen Y, Latha LY, Jothy SL, Sasidharan S. Hepatoprotective potential of Clitoria ternatea leaf extract against paracetamol induced damage in mice. Molecules 2011;16(12):10134-45.

21. Mahdi-Pour B, Jothy SL, Latha LY, Chen Y, Sasidharan S. Antioxidant activity of methanol extracts of different parts of Lantana camara. Asian Pac J Trop Biomed 2012;2(12):960-5.

22. Tundis R, Menichini F, Bonesi M, Conforti F, Statti G, Menichini F, et al. Antioxidant and hypoglycaemic activities and their relationship to phytochemicals in Capsicum annuum cultivars during fruit development. LWT Food Sci Technol 2013;53(1):370-7.

23. Bustanji Y, Issa A, Mohammad M, Hudaib M, Tawah K, Alkhatib $\mathrm{H}$, et al. Inhibition of hormone sensitive lipase and pancreatic lipase by Rosmarinus officinalis extract and selected phenolic constituents. J Med Plant Res 2010;4(21):2235-42.

24. Jaradat N, Zaid AN, Hussein F, Zaqzouq M, Aljammal H, Ayesh O. Anti-lipase potential of the organic and aqueous extracts of ten traditional edible and medicinal plants in Palestine; a comparison study with orlistat. Medicines 2017;4(4):89.

25. Masella R, di Benedetto R, Vari R, Filesi C, Giovannini C. Novel mechanisms of natural antioxidant compounds in biological systems: Involvement of glutathione and glutathione-related enzymes. J Nutr Biochem 2005;16(10):577-86.

26. Dai J, Mumper RJ. Plant phenolics: Extraction, analysis and their antioxidant and anticancer properties. Molecules 2010;15(10):7313-52.

27. Prior RL, Wu X, Schaich K. Standardized methods for the determination of antioxidant capacity and phenolics in foods and dietary supplements. J Agric Food Chem 2005;53(10):4290-302.

28. Ou B, Huang D, Hampsch-Woodill M, Flanagan JA, Deemer EK. Analysis of antioxidant activities of common vegetables employing oxygen radical absorbance capacity (ORAC) and ferric reducing antioxidant power (FRAP) assays: A comparative study. J Agric Food Chem 2002;50(11):3122-8.

29. Huang D, Ou B, Prior RL. The chemistry behind antioxidant capacity assays. J Agric Food Chem 2005;53(6):1841-56.

30. Aberoumand A, Deokule SS. Comparison of phenolic compounds of some edible plants of Iran and India. Pak J Nutr 2008;7(4):582-5.

31. Loizzo MR, Tundis R, Bonesi M, Menichini F, Mastellone V, Avallone L, et al. Radical scavenging, antioxidant and metal chelating activities of Annona cherimola Mill. (cherimoya) peel and pulp in relation to their total phenolic and total flavonoid contents. J Food Compost Anal 2012;25(2):179-84.

32. Soong YY, Barlow PJ. Antioxidant activity and phenolic content of selected fruit seeds. Food Chem 2004;88(3):411-7.

33. Tsuda T. Regulation of adipocyte function by anthocyanins; possibility of preventing the metabolic syndrome. J Agric Food Chem 2008;56(3):642-6.

34. Abumrad NA, Nassi F, Marcus A. Digestion and absorption of dietary fat, carbohydrate and protein. In: Feldman M, Friedman LS, Brandt LJ editors. Sleisenger and Fordtran's gastrointestinal and liver disease. 10th ed. Philadelphia, USA: Saunders Elsevier; 2016.

35. Dhurandhar NV, Schoeller D, Brown AW, Heymsfield SB, Thomas D, Sorensen TI, et al. Energy balance measurement: When something is not better than nothing. Int $\mathrm{J}$ Obes 2015;39(7):1109-13.

36. Villa-Ruano N, Zurita-Vásquez GG, Pacheco-Hernández Y, Betancourt-Jiménez MG, Cruz-Durán R. Anti-lipase and antioxidant properties of 30 medicinal plants used in Oaxaca, México. Biol Res 2013;46(2):153-60.

37. Sergent T, Vanderstraeten J, Winand J, Beguin P, Schneider YJ. Phenolic compounds and plant extracts as potential natural anti-obesity substances. Food Chem 2012;135(1):68-73. 